\title{
Venta de Borondo (Daimiel, Ciudad Real). Actuaciones arqueológicas para la recuperación de un bien singular
}

\author{
Venta de Borondo (Daimiel, Ciudad Real). Archaelogical \\ perfomances for the restoring of a singular asset
}

\author{
MIGUEL TORRES MAS \\ Motilla del Azuer/Ayuntamiento de Daimiel \\ migueltorresarqueologo@gmail.com \\ DAVID CEJUDO LORO \\ Asociación Cultural Venta de Borondo \\ cejudo.david@gmail.com \\ M. ${ }^{a}$ ISABEL ANGULO BUJANDA \\ misabelangulo@gmail.com \\ HONORIO ÁLVAREZ GARCÍA \\ honorioalvarez@gmail.com
}

Resumen: La Venta de Borondo (Daimiel, Ciudad Real) es uno de los últimos exponentes de una tipología arquitectónica representativa de la época bajomedieval-moderna, como lo fueron las ventas de llanura. En su conjunto, en el que destaca el torreón occidental, se pueden identificar las particularidades que atesoraron estas manifestaciones y que, entre otras consideraciones, pudieron servir de inspiración a Miguel de Cervantes para su recreación dentro de la celebérrima obra Don Quijote de la Mancha.

A pesar de su trascendencia, la ausencia de labores de mantenimiento en su interior ha causado el deterioro progresivo de sus estructuras, con riesgo de colapso en determinadas zonas. Por estas razones, desde el año 2017, se están emprendiendo diversas acciones con el objetivo de estudiar, preservar y difundir este conjunto patrimonial tan emblemático. A través de este artículo tratamos de dar a conocer las singularidades de este inmueble, así como describir las actuaciones que se están llevando a cabo en torno al mismo y que tratan de fomentar un legado excepcional.

Palabras clave: construcción civil, sitio histórico, torre, tapial, Daimiel.

Recibido: 17 de enero de 2020; aceptado: 25 de mayo 2020; publicado: 30 de septiembre de 2020.

Revista Historia Autónoma, 17 (2020), pp. 51-73

e-ISSN: 2254-8726; $\underline{\text { https://doi.org/10.15366/rha2020.17.003 }}$ 
Abstract: Venta de Borondo (Daimiel, Ciudad Real, Spain) is one of the last exponents of a late medieval and early modern architectural typology, as were the plains inns. In this historic site, in which the western tower stands out, it is possible to identify the particularities of these kind of constructions, which could have inspired Miguel de Cervantes to recreate one of them in its worldwide known work Don Quixote of La Mancha.

Despite its transcendence, the lack of maintenance works has caused a progressive deterioration of its structures, with a serious risk of collapse in certain areas. For these reasons, since 2017, several actions have been undertaken with the aim of studying, preserving and communicating this emblematic heritage site. Through this article, we try to raise awareness of the singularities of this building, as well as to describe the works that are being carried out to preserve this exceptional legacy.

Keywords: civil construction, historical site, tower, rammed earth, Daimiel.

\section{La Venta de Borondo en su contexto territorial}

La Venta de Borondo se encuentra emplazada a unos $16 \mathrm{~km}$ al sur del núcleo urbano de Daimiel, en el extremo meridional de su término, razón por la que se encuentra muy próxima al límite con otros municipios como Manzanares, Almagro y Bolaños, todos ellos en la provincia de Ciudad Real (Castilla-La Mancha). Además, durante un tiempo llegó a constituir el límite entre la encomienda de Ureña y la población de Moratalaz, actualmente desaparecidas. Se localiza dentro del paraje localmente conocido como "Campo de Ureña" y cercana a la falda norte de la Sierra Pelada, en pleno Campo de Calatrava.

Figura 1: Mapa con la localización de la Venta de Borondo.
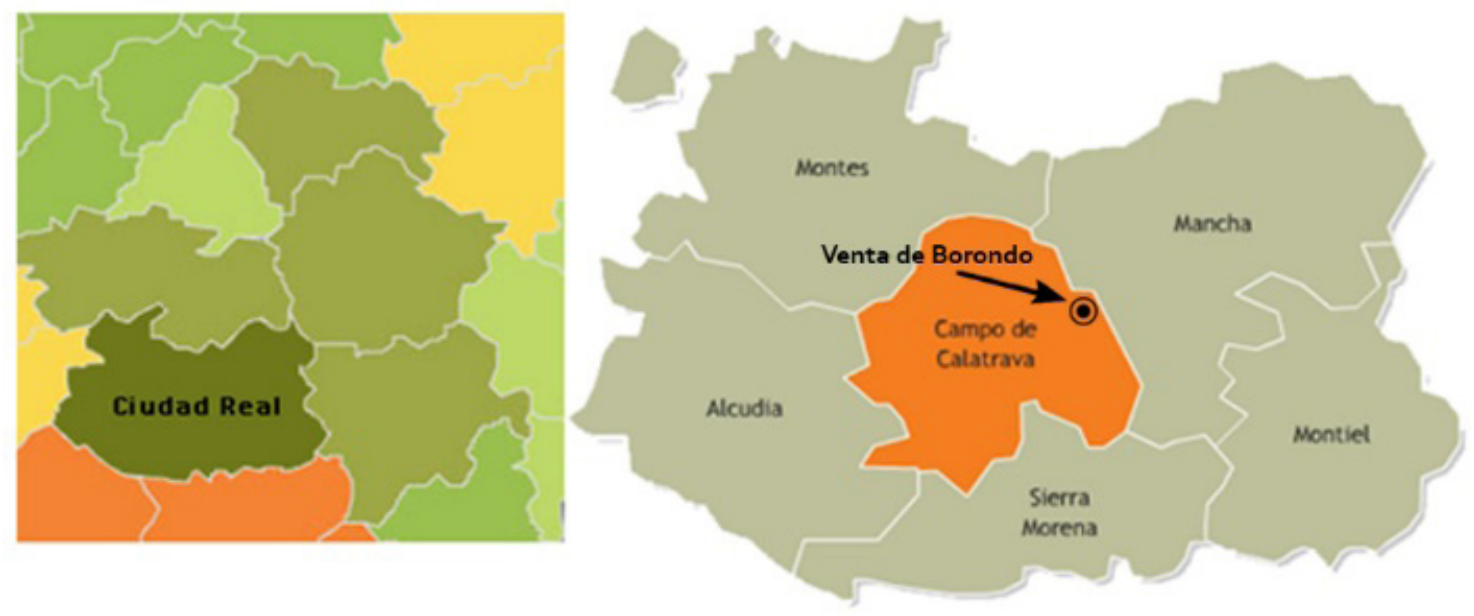

Fuente: Elaboración propia. 
A lo largo de la historia ha representado un punto estratégico a nivel comarcal, ya que en torno a la Venta discurren diversas rutas e itinerarios de cierta trascendencia. Así, por sus inmediaciones se sitúa el "Camino Real de Alicante", que unió Ciudad Real con aquella ciudad, correspondiendo concretamente al tramo denominado "Camino de Almagro", que permitió durante varios siglos la conexión entre esta villa y las de Bolaños y Manzanares. Unos $100 \mathrm{~m}$ al norte transita el "Camino de las Carretas", conocido también como Ureña o del Pardillo, que tuvo un importante tráfico carretero durante determinadas etapas.

Hacia el sur, al otro lado de las estribaciones de Sierra Pelada, encontramos la "Cañada Real Soriana Oriental", una de las vías de uso tradicional dentro de los circuitos trashumantes, en vigencia desde época medieval. Este movimiento, basado en el desplazamiento de ganado entre el norte y el sur peninsular para aprovechar la idoneidad del pasto según la época del año, implicó la configuración de un sistema cíclico de traslado de animales y personas. Asimismo, esta actividad necesitó el desarrollo de infraestructuras viarias que facilitaran el abastecimiento de una logística precisa. Estas instalaciones presentaron unas dimensiones heterogéneas adaptadas al medio físico, así como a las exigencias de un sector productivo concreto: el ganadero $^{1}$. Igualmente, fue importante la disposición de una corporación que reglamentase pautas y procedimientos considerados esenciales en esta tarea, expresada en la articulación del Honrado Concejo de la Mesta².

En los mismos términos, la red de comunicaciones diseñada entre diferentes regiones favoreció la habilitación de establecimientos que permitieran el descanso, alojamiento y provisión de los viajeros. A esta demanda parece que respondieron las ventas de fase bajomedievalmoderna, que se extendieron a lo largo de diversos puntos de España como la actual Castilla-La Mancha3 ${ }^{3}$ La relevancia de estas edificaciones facilitó su referencia en fuentes documentales de la época, como sucedió con el ejemplo daimieleño.

Los cambios experimentados a nivel político, económico y social a partir del siglo XIX, pero sobre todo la introducción de innovaciones en los medios de transportes y la redefinición de las rutas configuradas, implicaron el ocaso de estos "referentes camineros", por lo que muchos de ellos acabaron abandonándose. Esta situación significó el fin progresivo de estas construcciones, contribuyendo a su desaparición del espacio físico y simbólico en el que surgieron. Por desgracia, en la actualidad, la mayor parte de los casos pertenecientes a esta

\footnotetext{
${ }^{1}$ Las cañadas reales castellanas se subdividían en bifurcaciones menores llamadas cordeles y veredas. No obstante, se puede documentar la existencia de un alto número de vías más estrechas, de denominación heterogénea y carácter local, generando una red de vasos comunicantes en la que los pastores trashumantes optaban por un trazado en virtud del contexto climático, político o económico de cada momento. García Martín, Pedro, "Cañadas, trashumancias y cultura mesteña”, en Ambienta: La Revista del Ministerio de Medio Ambiente, 120 (2017), pp. 14-23.

${ }^{2}$ Así, en 1273, el rey Alfonso X “el Sabio" constituyó el "Honrado Concejo de la Mesta”, como un gremio constituido como marco legal para todos los ganaderos, con el que se intentaba evitar, entre otras cuestiones, los conflictos latentes entre agricultores y ganaderos por el tránsito de los rebaños por las tierras de los primeros. Arcos Domínguez, Ma Carmen y Manuel Molina Cañadas, Montes Norte. Un patrimonio por descubrir, Ciudad Real, Gráficas Garrido, 2011, p. 42.

${ }^{3}$ García Sáez, Joaquín Francisco, Las Ventas: Una arquitectura rural singularizada por su función. Las ventas en la provincia de Albacete, Toledo, Colegio Oficial de Arquitectos de Castilla-La Mancha, 2008.
} 
tipología se encuentran desaparecidos, en mal estado de conservación o tienen alterada su composición, siendo la Venta de Borondo uno de los escasos testimonios que mantiene la integridad y singularidad de estos inmuebles ${ }^{4}$. Además, en su estructura se pueden advertir las características que han conformado la arquitectura vernácula de esta región ${ }^{5}$. Estas fortalezas, así como todas las singularidades que atesora, permitieron su catalogación como Bien de Interés Cultural en el año $2007^{6}$.

\section{La Venta de Borondo en la historia}

Desconocemos con exactitud el origen del actual edificio, aunque podemos situar su génesis en torno a los estadios finales del mundo medieval o inicios de la época moderna. A este respecto, la primera mención documental la encontramos en las Relaciones topográficas de Felipe II, concretamente en la contestación 25 sobre el término de Daimiel ${ }^{7}$.

No obstante, en sus alrededores se han podido localizar elementos materiales que inferirían en la ocupación de su espacio físico desde fechas anteriores. Así, por ejemplo, se han documentado fragmentos de cerámica asociados al horizonte crono-cultural íbero regional. Destaca el hallazgo de diversos galbos con la típica decoración de bandas geométricas-circulares con engobe de tonalidad vinosa ${ }^{8}$. También se han localizado piezas de adscripción romana, como terra sigillata, tegula y material latericio. De todos modos, el carácter parcial y secundario de estos descubrimientos, bien localizados de manera superficial, bien formando parte de los tapiales de los paramentos de la venta, no permiten concretar el tipo de establecimiento que se configuraría en torno a estas etapas. A este respecto, quizás podría relacionarse con las vías de comunicación peninsulares articuladas durante este período, algunas de las cuales transitarían por esta comarca ${ }^{9}$. Igualmente, tampoco es posible determinar si este poblamiento estaría ya en vigencia durante el contexto oretano de la Edad del Hierro o, en cambio, se trataría de modelos

\footnotetext{
${ }^{4}$ Cejudo Loro, David, "Venta de Borondo: origen y evolución hasta nuestros días", en II Jornadas de Historia de Daimiel, Ayuntamiento de Daimiel, 2013, p. 71.

${ }^{5}$ Jérez García, Oscar, Arquitectura Popular Manchega, Ciudad Real, Diputación de Ciudad Real, 2004.

${ }^{6}$ Resolución publicada en DOCM con fecha 14-12-2007. Su catalogación se debe a que responde a un inmueble “singular y destacado dentro del patrimonio de esta región”. Queda recogido como Monumento, al corresponder con una "construcción u obra producto de la actividad humana, de sobresaliente interés histórico, artístico, arquitectónico o arqueológico".

${ }^{7}$ Viñas Mey, Carmelo y Ramón Paz, Relaciones histórico-geográficas-estadísticas de los pueblos de España hechas por iniciativa de Felipe II. Ciudad Real. Biblioteca virtual de la Universidad de Castilla-La Mancha, 1971, p. 13, «www.uclm.es/ceclm/b virtual/libros/Relaciones CR/index.htm» [Consultado 29 de septiembre de 2019]. ${ }_{8}^{8}$ Rodríguez González, David, "Notas sobre el poblamiento de época ibérica en Daimiel (Ciudad Real)", en III Jornadas de Historia de Daimiel, Ayuntamiento de Daimiel, 2015, p. 36.

${ }^{9}$ Torres Mas, Miguel, "El poblamiento protohistórico y la romanización en los Ojos del Guadiana", en Desde el Árbol Gordo, 11 (2013), pp. 34-38.
} 
de pervivencia de la cultura indígena íbera, que tuvo continuidad durante las primeras fases de la romanización de este territorio ${ }^{10}$.

Siendo conscientes de las limitaciones de los resultados obtenidos, las interpretaciones nos señalarían la importancia de este lugar para el asentamiento humano desde tiempos pretéritos. En virtud de estas ventajas, quedó definido un establecimiento de características desconocidas en la actualidad, que podría estar relacionado con los itinerarios que a nivel peninsular se venían formalizando desde etapas protohistóricas ${ }^{11}$.

Este emplazamiento propicio estuvo presente también en época bajomedieval, cuando el fortalecimiento de las conexiones entre Castilla y Andalucía generó la necesidad de habilitar hospederías en el recorrido, razón por la cual surgiría la Venta de Borondo. Su funcionamiento se situó dentro de una cronología, siglos XV y XVI, en la que estos albergues fueron extendiéndose por diferentes regiones ${ }^{12}$, pasando a convertirse en referentes distintivos del paisaje. Así, en las Relaciones topográficas de Felipe II encontramos alusiones a la existencia de ventas en el entorno de Daimiel y su contexto geográfico más próximo. Gracias a este texto conocemos el nombre de algunas, como en este caso, y ciertas particularidades de su arquitectura, como sus paredes encaladas y zócalos de color añil, que quedarían integrados en "el horizonte manchego"13. No menos indicadoras son las profusas referencias efectuadas por Miguel de Cervantes a estas construcciones en su obra Don Quijote de La Mancha ${ }^{14}$ :

\footnotetext{
[...] vió no lejos del camino por donde iba una venta, que fue como si viera una estrella, que a los portales, si no a los alcázares de su redención, le encaminaba. Dióse priesa a caminar, y llegó a ella a tiempo que anochecía [..] luego que vió la venta se le representó que era un castillo con sus cuatro torres y chapiteles de luciente plata, sin faltarle su puente levadizo y honda cava, con todos aquellos adherentes que semejantes castillos se pintan. ${ }^{15}$
}

En suma, parece atestiguado que la Venta de Borondo, al menos desde el siglo XVI, cumplió funciones de albergue en relación con diferentes recorridos que transitaban por este paraje. Fueron, además, arterias que permitieron el tránsito de personas, ganados, mercancías, o incluso también de ideas, aspectos que potenciaron su trascendencia a lo largo del tiempo.

Esta orientación marcó su arquitectura, generando una huella que se ha mantenido hasta nuestros días. El paso del tiempo, las eventualidades y las modas fueron introduciendo cambios o reformas en su construcción, bien con el objetivo de adaptarse a nuevas necesidades o en

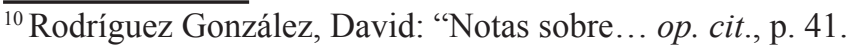

${ }^{11}$ Carrasco Serrano, Gregorio, “Aportación al estudio de las vías romanas de Toledo y Ciudad Real”, en Hispania antigua, 36 (2012), pp. 151-162.

${ }^{12}$ Cejudo Loro, David, "Venta de Borondo: ... op cit., p. 75.

${ }^{13}$ Viñas Mey, Carmelo y Ramón Paz, Relaciones histórico-geográficas... op. cit.

${ }^{14}$ De todos modos, no podemos inferir con certeza que Miguel de Cervantes Saavedra se basara específicamente en esta edificación para trasladar los episodios de las andanzas del "Caballero de la Triste Figura", aunque debido a los numerosos viajes emprendidos por el autor, existe la posibilidad que conociera de primera mano esta venta.

${ }^{15}$ Cervantes Saavedra, Miguel, 1605, El ingenioso hidalgo don Quijote de La Mancha, parte I, capítulo 2.
} 
virtud de las posibilidades técnicas, económicas y estéticas de las gentes vinculadas con el inmueble ${ }^{16}$.

Una fecha importante en su historia lo encontramos en el año 1674, ya que sus paredes fueron testigos de un acontecimiento notable, acogiendo a representantes de las villas de Almagro, Daimiel, Manzanares y Moral para acordar amojonar y deslindar el término de Moratalaz $^{17}$, cuyos límites se situaban cercanos ${ }^{18}$.

Durante el siglo XVIII encontramos menciones a su recinto, como en la obra del geógrafo Tomás López, con la plasmación de varios mapas cartográficos sobre La Mancha y el Campo de Calatrava ${ }^{19}$. En ellos aparece recogido su nombre y localización. Incluso, este autor llegó a situar en este punto el episodio del Quijote donde el personaje literario Alonso Quesada fue armado caballero. Asimismo, en el "Itinerario Español, o Guía de Caminos" de José Matías Escribano es nombrada esta edificación ${ }^{20}$.

Durante la segunda mitad del siglo XIX, las rutas históricas mencionadas perdieron la trascendencia que habían ostentado. La aparición de nuevos trazados con mejores firmes alteró su consideración como centros camineros referenciales. En este caso, el impulso de una carretera a unos $2,5 \mathrm{~km}$ al norte ${ }^{21}$, significó el traslado del volumen del tráfico a este recorrido, implicando el abandono progresivo de los caminos antiguos. Por esta razón, la circulación quedó reducida al tránsito de propietarios de las fincas del contorno, como sigue ocurriendo hoy en día.

Este escenario implicó una reorientación en la concepción de la venta como alojamiento. A partir de este momento pasó a tener una dedicación agropecuaria más exclusiva, con el objetivo de aprovechar las potenciales posibilidades que ofrecía el entorno. Esta circunstancia provocó la modificación de espacios interiores, sustituyendo habitaciones empleadas como alojamientos por salas dedicadas a cuadras, pajares o abrevaderos. No obstante, mantuvo buena parte de la arquitectura primitiva, como dimensiones de espacios, materiales y técnicas constructivas. De todos modos, es probable que conservara alguna prerrogativa con respecto a su uso

\footnotetext{
${ }^{16}$ Cada transformación experimentada en el inmueble ha generado una nueva arquitectura que inexorablemente respondió a aquellas variables funcionales, constructivas o formales que justificaron su modificación. De la misma forma, en cada proceso se produce un contexto diferente en el que los materiales conservados del diseño precedente se integran en el proyecto ex novo.

${ }^{17}$ Moratalaz fue una entidad de origen islámico, época en la que parece que constituyó una unidad territorial que contó con una población dispersa y orientación eminentemente agrícola. A partir del siglo XIII pasó al control de la Orden de Calatrava, reduciendo progresivamente sus límites y número de vecinos hasta quedar prácticamente despoblada en el siglo XVI. Este abandono generó un escenario de conflictos por su territorio entre las localidades próximas. Almagro Vidal, Clara, "Un trayecto de doble sentido: relaciones entre Daimiel y Moratalaz a finales de la Edad Media”, en II Jornadas de Historia de Daimiel, Ayuntamiento de Daimiel, 2013, pp. 59-69.

${ }^{18}$ García-Consuegra García-Consuegra, Mariano, "La Venta que parecía castillo", en Revista el Olivo, (2010), pp. 18-19.

${ }^{19}$ López, Tomás, Mapa de una porción del Reyno de España que comprehende los parages por donde anduvo Don Quijote, y los sitios de sus aventuras [Material cartográfico] / Delineado por D. Tomás López Geógrafo de S. M. según las observaciones hechas sobre el terreno por D. Joseph de Hermosilla Capitán de Ingenieros|, Madrid, Se, 1780 .

${ }^{20}$ Escribano, José Matías, Itinerario Español o Guía de Caminos para ir desde Madrid a todas las Ciudades y Villas importantes de España: y para ir de unas ciudades à otras; y à algunas Cortes de Europa, Madrid, Imprenta de Miguel Escribano, 1767.

${ }^{21}$ Esta carretera aparece ya ilustrada en el Mapa Topográfico Nacional de 1888, hoja 785.
} 
anterior. Así, según testimonios orales, se tiene constancia del estabulamiento ocasional en los exteriores de rebaños procedentes de los páramos sorianos, sur de la provincia de Ciudad Real o de Extremadura ${ }^{22}$. Incluso, según estas fuentes, las gentes asociadas a esta práctica, quizás acogiéndose a derechos tradicionales, podían utilizar para su descanso las infraestructuras auxiliares de este complejo. El retroceso de este modus viviendi, la introducción de innovaciones en las fórmulas de circulación, con la mecanización de medios de transporte y vehículos, y la progresiva intensificación de la ganadería, así como los cambios experimentados en el paradigma económico y social español en las últimas décadas de la centuria pasada, acabarían definitivamente con el tránsito trashumante por estos parajes.

Figura 2: Fotografía Venta de Borondo, 1953.

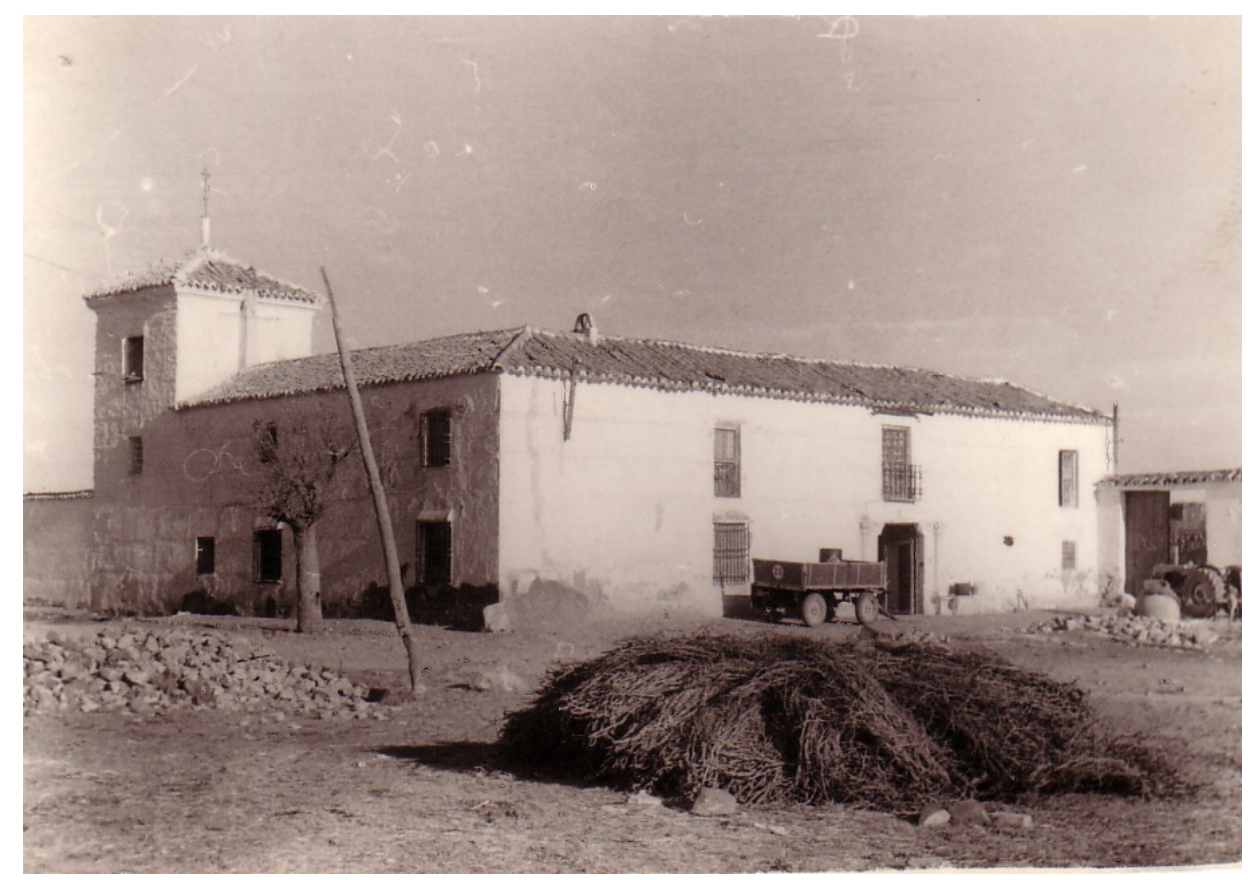

Fuente: Familia López Bautista.

\begin{abstract}
${ }^{22}$ Así nos lo comentan los herederos familiares de los antiguos propietarios. La incorporación de fuentes orales para la investigación histórica ha sido un tema que ha generado un cierto debate entre los especialistas. En España la década de 1980 significó un periodo de eclosión de esta materia, con la organización de los primeros congresos y proyectos a nivel nacional. Desde entonces se han celebrado multitud de conferencias, seminarios y cursos, configurándose un número importante de equipos de trabajo como el Seminario de Fuentes Orales de Madrid, GIFO de Valencia, Seminario de Fuentes Orales y Gráficas de la UNED, entre otros, incluso dentro de instituciones no académicas, como la pionera Sección de Historia Oral del Instituto Municipal de Historia de Barcelona. La creación en 1989 de la revista Historia y Fuente Oral, posteriormente Historia, Antropología y Fuente Orales, representó todo un hito para esta área. En la actualidad son numerosos los proyectos que encontramos en torno a esta temática como Seminario de Fuentes Orales de la Universidad Complutense de Madrid, AHOA, Mujer y Memoria, Banc Audiovisual de Testimonis o el Archivo de la Palabra. En líneas generales, se trata de un método de investigación basado en la grabación de testimonios orales en el marco de entrevistas. Ferrando Puig, Emili, Fuentes orales e investigación histórica: orientaciones metodológicas para crear fuentes orales de calidad en el contexto de un proyecto de investigación histórica, Barcelona, Ediciones del Serbal, 2006. Aunque es cierto que a nivel nacional se lamenta la falta de un debate teórico más profundo y un movimiento de renovación historiográfica, el desarrollo de esta técnica ha permitido grandes avances en el campo de la historia sociopolítica. A este respecto, puede resultar interesante para reconstruir el pasado, sobre todo para aportar otros enfoques y puntos de vista, aunque sin obviar la crítica epistemológica. Alía Miranda, Francisco, Técnicas de investigación para historiadores. Las fuentes de la Historia, Madrid, Síntesis, 2017. En este caso se optó por una entrevista no dirigida (libre) sobre los actuales propietarios de la Venta de Borondo. Por edad, todos ellos recuerdan aspectos interesantes sobre el funcionamiento de la Venta de Borondo durante la segunda mitad del siglo XX.
\end{abstract}


El fin de las actividades relacionadas con la historia de esta construcción, con la pérdida de la funcionalidad para la que fue concebida, implicó su declive progresivo. Esta situación resultó más evidente a principios del siglo xxI, cuando la prolongada ausencia de labores de mantenimiento, unida al impacto de agentes erosivos ambientales sobre su composición, provocó el deterioro paulatino de todo su conjunto, con el riesgo de colapso de estructuras y la amenaza de ruina absoluta ${ }^{23}$. Por estas razones, varios ciudadanos de Daimiel en el año 2016 decidieron constituir la Asociación Cultural "Venta de Borondo y Patrimonio Manchego", con el objetivo fundamental de promover la salvaguarda y la valorización de este inmueble.

\section{La edificación de la Venta de Borondo}

Grosso modo, en la actual propiedad podemos apreciar buena parte de las características de las "ventas de llanura" de cronología bajomedieval-moderna. Además, como hemos comentado supra, representa una de las últimas manifestaciones existentes en estos momentos. Por otra parte, su diseño, evolución y configuración responde a las directrices propias de las construcciones vernáculas manchegas, por lo que constituye también un modelo óptimo para identificar las particularidades de esta tipología.

La venta se encuentra articulada por un edificio principal de planta rectangular. Cuenta con dos alturas, un patio interior y torreón en la esquina suroeste, punto icónico del sitio. En torno a esta construcción se distribuyen una serie de estancias secundarias, erigidas para una función agropecuaria.

Al interior del ámbito preferencial se accedía desde la fachada oriental, a través de una puerta de doble hoja en su punto central, flanqueada por un pórtico de sillería decorado con basas, medias columnas adosadas al paramento, capitel, friso y escudo de armas sobre el dintel. Por desgracia, algunas de estas piezas han sido expoliadas. Constituye la sección que cuenta con una ornamentación más relevante, destacando la presencia de unas ménsulas con simbología de arpías o arpíos. El desarrollo actual de las investigaciones no permite establecer si se trataría de una composición ex professo, lo que denotaría un importante nivel económico de sus propietarios, o pudo trasladarse íntegramente desde otro lugar, como pudo ser la ermita de Nuestra Señora de Ureña, santuario que se situaba relativamente cercano a esta zona. A partir del siglo XVIII, este templo experimentó una progresiva decadencia hasta que quedó prácticamente en ruinas durante el siglo $\mathrm{XIX}^{24}$. Su ocaso favoreció que elementos presentes en

\footnotetext{
${ }^{23}$ De hecho, llegó a estar situado en la "Lista Roja del Patrimonio Hispania Nostra", clasificación que mantuvo hasta el año 2018. Actualmente, debido a las acciones realizadas desde el 2017, ha pasado a formar parte de la "Lista Verde" https://listarojapatrimonio.org/ficha/venta-de-borondo/ [Consultado 17 de octubre de 2019].

${ }^{24}$ Cejudo Loro, David, "Venta de Borondo:... op. cit., p.73.
} 
el mismo fueran trasladados hacia otros sitios. Por ejemplo, la talla de la Virgen venerada en esta iglesia pasó a la parroquia de San Pedro Apóstol de Daimiel, ocupando la parte central del retablo, ubicación que denota la relevancia otorgada por su adquisición ${ }^{25}$. Con respecto a los motivos iconográficos, la arpía o harpía simboliza un ser fantástico clasificado entre los entes "híbridos y monstruosos", generalmente asociado a unas connotaciones negativas. Su representación es heterogénea, como así puede advertirse tanto en las descripciones como en sus expresiones formales, ya que habitualmente suele confundirse con la iconografía de la mujerave o sirena ${ }^{26}$. Por regla general, se conforma con una cabeza de mujer, cuerpo femenino o de ave y cola de serpiente o escorpión, pudiendo tener incluso patas de ave de presa. Esta temática parece tener su origen en las culturas orientales ${ }^{27}$, desde las que fue adoptada por el mundo grecorromano, en el que gozó de cierta repercusión. Posteriormente, la Iglesia Católica, dentro de la disposición que otorgó a los espacios sagrados de un sentido didáctico y moralizante para la instrucción de los fieles, contribuyó a la asimilación artística de motivos provenientes del mundo clásico, en el que las divinidades mitológicas recogían los vicios y la depravación de la sociedad de la época ${ }^{28}$. Por esta razón, estas figuras participaron de manera activa como elementos simbólicos de los recintos de culto. Fue el caso de los capiteles de la otra parroquia local, Santa María ${ }^{29}$. En su interior, en las molduras de estas piezas se advierte la presencia de seres monstruosos, como una sirena, una cara humana grotesca, niños jugando de manera "indecorosa" con un perro, o formas monstruosas. Se trataría de elementos que ostentarían un carácter pedagógico y moralizante para la comunidad religiosa, sin descartar un sentido devocional integral, contando con un significado específico dentro del período en el que fueron proyectados $^{30}$. La vinculación de estos ornamentos con lugares de culto reforzaría la tesis de la pertenencia del grupo de la Venta de Borondo con un santuario, como podría suceder con el próximo de Nuestra Señora de Ureña, que, ante el abandono del mismo, determinados objetos y ornamentos fueran depositados en este inmueble.

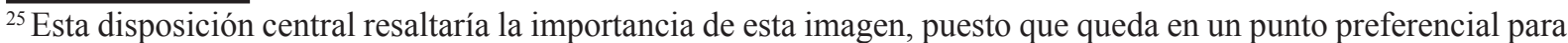
la vista del fiel, dentro de una jerarquización del recinto sagrado en el que las representaciones devocionales son distribuidas en planos alegóricos según su trascendencia. Moreno Moreno, Andrés J., Milagros y exvotos de un pueblo manchego, Ciudad Real, Biblioteca de Autores Manchegos, 1989, p. 89.

${ }^{26}$ García-Consuegra García-Consuegra, Mariano, "La sirena varada", en IV Jornadas de Historia de Daimiel, Ayuntamiento de Daimiel, 2018, p. 66.

${ }^{27}$ Afirma Diana Oliveros que en las antiguas civilizaciones de Mesopotamia, Egipto e India estos seres híbridos contaron con cierta aceptación. Desde estas culturas fueron recogidas por la mitología griega y romana, para posteriormente integrase en los espacios sagrados del mundo románico, como en canecillos y capiteles, e incluso en el arte y literatura islámica. Olivares Martínez, Diana, "Las arpías", en Revista Digital de Iconografía Medieval, 6, 11 (2014), pp. 1-12.

${ }^{28}$ Minerva Saenz señala que las arpías pasaron a la Edad Media como alegorías de pecados de culpa y castigo, como la codicia, el fraude y la falsedad. Sáenz Rodríguez, Minerva, "La imagen de la mujer en la escultura monumental románica de La Rioja”, en Berceo, 147 (2004), p. 210.

${ }_{29}$ Junto con San Pedro Apóstol es una de las administraciones parroquiales en las que se encuentra dividida eclesiásticamente la ciudad de Daimiel. Se trata de una iglesia de origen gótico de planta basilical con tres naves paralelas y torre a los pies.

${ }^{30}$ Torres Mas, Miguel, Expiración. Los blancos en la Historia y la Semana Santa de Daimiel, Cofradía del Cristo de la Expiración y Nuestra Señora de los Dolores, 2016, p. 111.
} 
Figura 3: Detalle de puerta en fachada principal.

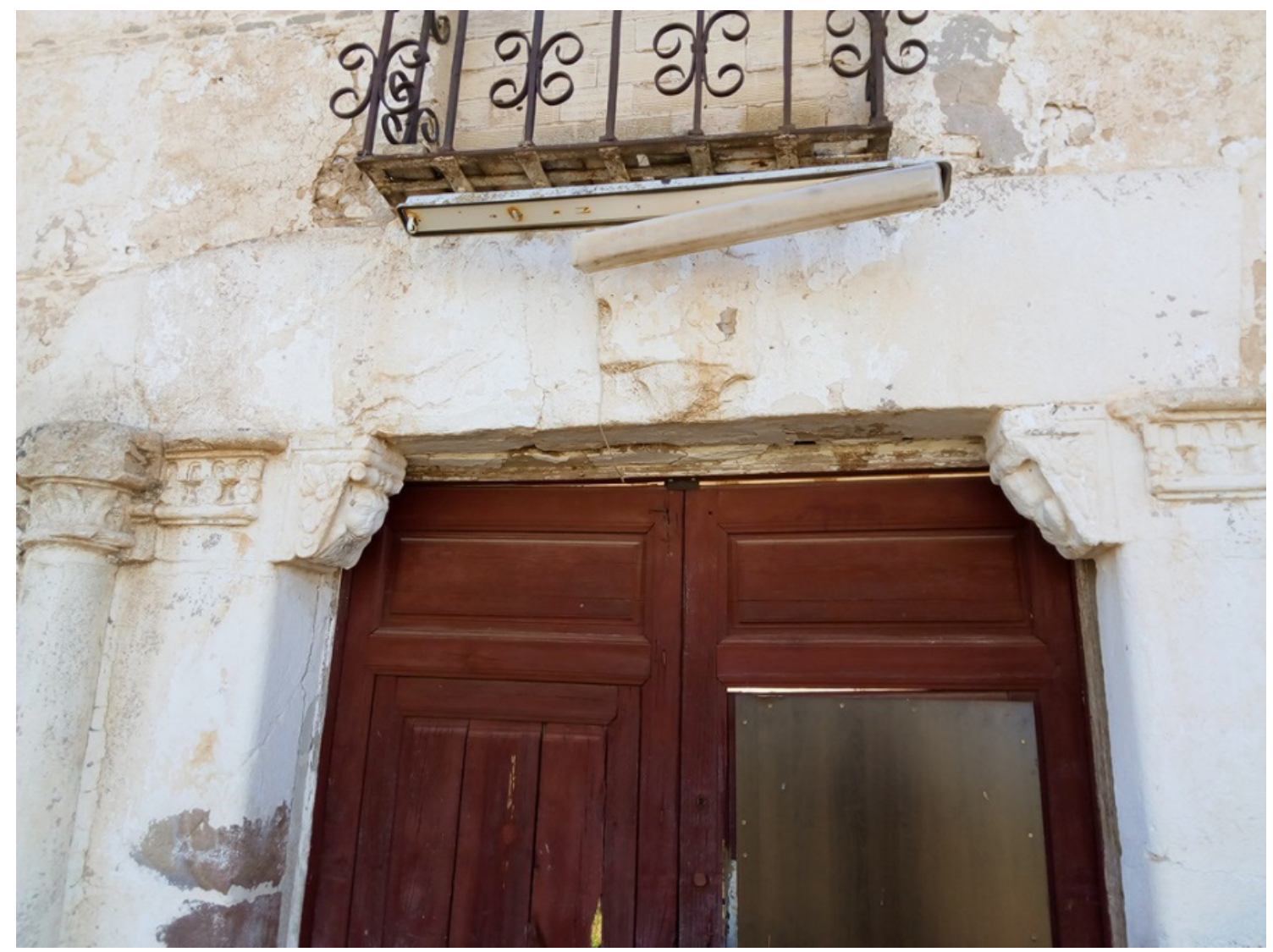

Fuente: Autores.

Retomando la descripción arquitectónica, en la fachada oriental, a ambos lados de la entrada, encontramos ventanas rectangulares de proporciones verticales con rejas de hierro salientes. También encontramos alrededor de la puerta dos poyetes o bancos de fábricas. La composición exterior presenta un dibujo con hueco central con dos ventanas laterales y tres vanos superiores de la cámara que coinciden aproximadamente con las oquedades inferiores. Se advierte una composición sencilla, pero en la que se distingue cierto nivel de planificación. Asimismo, delante de este punto, en relación con su importancia como zona de paso, aparece un pavimento formado por piedras calizas de mediano-pequeño tamaño trabadas con tierra apisonada.

Desde la nave oriental se tiene acceso al patio central. Este espacio abierto, siguiendo parámetros habituales en esta arquitectura, tuvo una función preferencial como distribuidor de estancias, a partir del cual se accedía a diferentes habitaciones interiores. En la planta más baja, en su último uso en el tiempo, fueron habilitadas salas destinadas a cocinas, cuadras, almacenes y habitaciones domésticas. Mientras el piso superior, al cual se accedía mediante dos escaleras, una interior de dos tramos al noreste y otra exterior de un tramo al sureste, fue aprovechado como dormitorios y cámaras. El suelo del patio fue dispuesto por un empedrado con tierra batida, 
similar al referenciado en la parte delantera de la fachada principal. Entre los objetos presentes en su perímetro es destacable una pila labrada en piedra, junto con una prensa o un brocal de pozo realizados en el mismo material. A pesar de su representatividad, es difícil estimar una cronología precisa de estos objetos pétreos debido a su evidente descontextualización.

Al suroeste de la construcción principal se dispone la torre, sin duda alguna el recurso emblemático del monumento. En origen pudo ostentar un papel estratégico como mirador que controlaba el entorno y las vías de comunicación que vertebraban este espacio. En este sentido, constituye un apreciable referente visual observable desde una larga distancia. Disponía de ventanas en los cuatro lados de los dos pisos superiores, aunque todas ellas, salvo las situadas en la pared meridional, fueron cegadas con posterioridad. La techumbre estaba formada por una estructura de madera sobre la que se habilitó una formación de pendiente a cuatro aguas mediante tableros de madera y tejas curvas de barro cocido. Destaca en su parte inferior el alero, realizado con yeso y cuerdas de esparto trenzadas. En pleno siglo xx su interior fue transformado como palomar, perdiendo la funcionalidad para la que fue concebido y alterando su disposición.

Figura 4: Primera planta edificio principal.

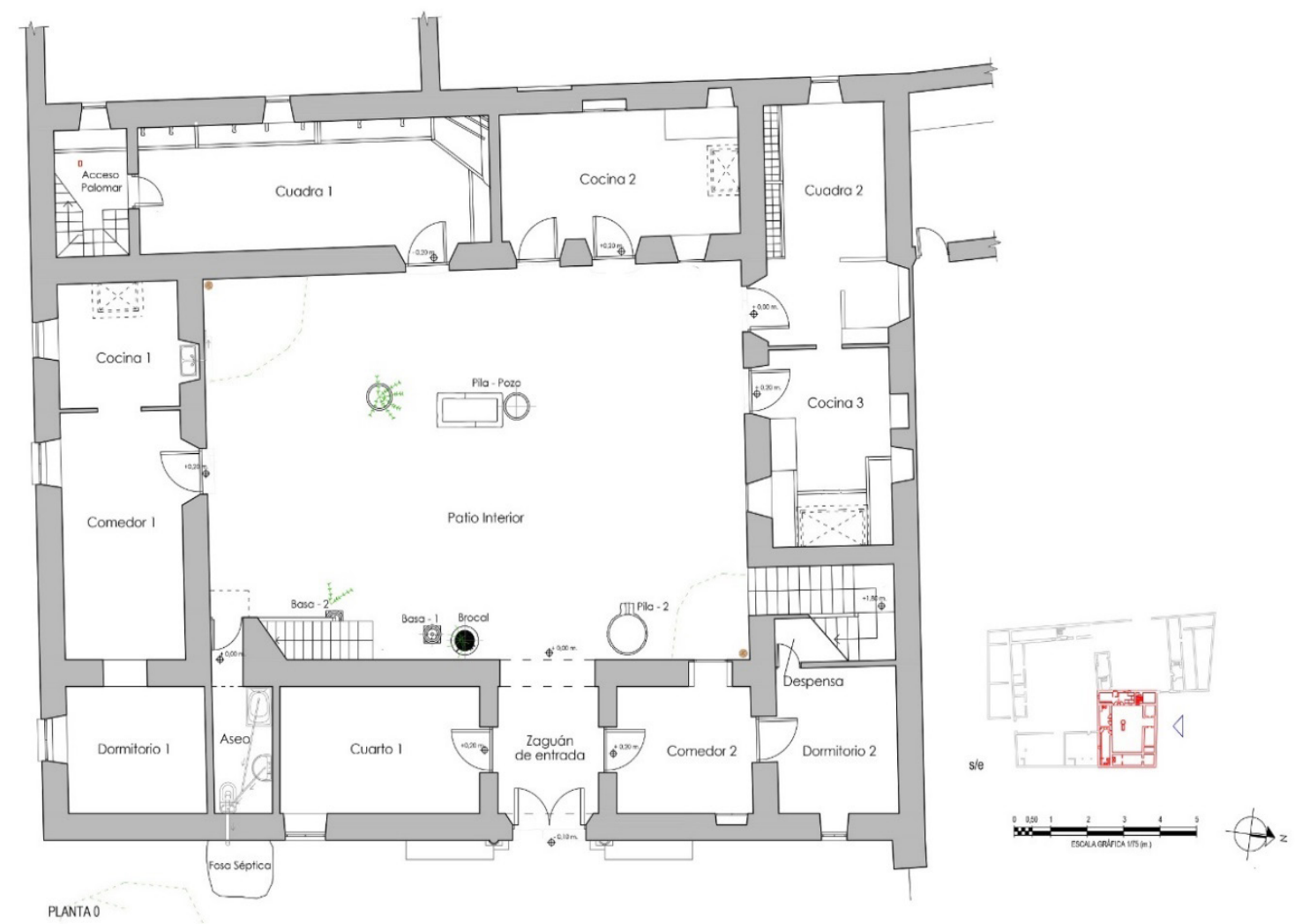

Fuente: David Cejudo. 
Figura 5: Segunda planta edificio principal.

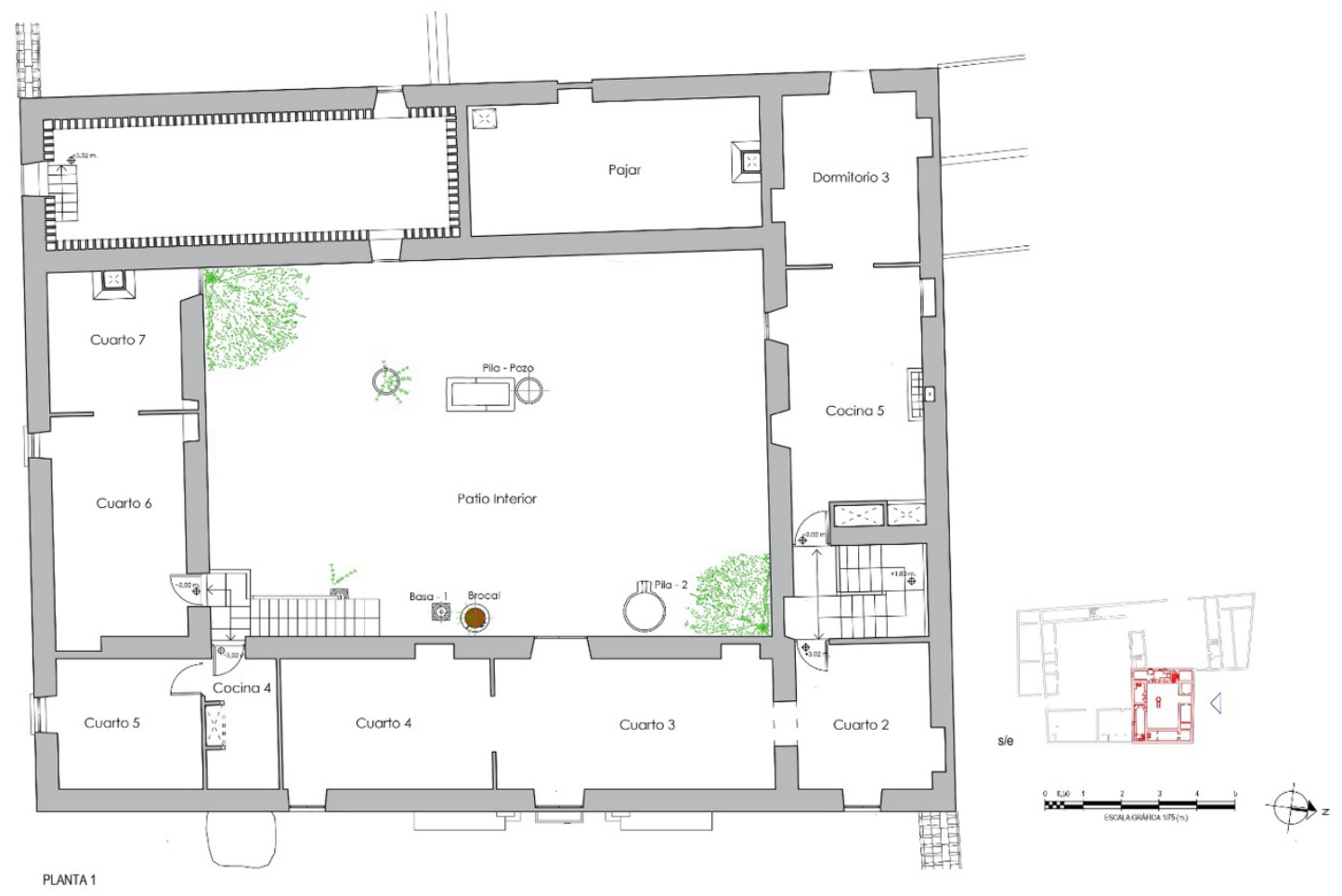

Fuente: David Cejudo

En sus paredes se instalaron nidales para albergar a las aves, quedando todo el interior diáfano. Entre estos llamativos elementos se han documentado dos tipos diferenciados, unos de obra ejecutados de forma rectangular y otros elaborados a partir de arcaduces cerámicos. Estas piezas cerámicas, por sus dimensiones y características, se sabe que fueron generadas ex professo para tal fin. Fue curiosa la elaboración de un sistema para la salida y entrada de estos animales, a través de un procedimiento que permitía la apertura y cierre de la ventana superior, mediante tres poleas y una cadena metálica, de manera eficaz y precisa, evitando el acceso de depredadores.

Por su parte, las naves fueron levantadas con mampostería de piedra caliza, tapial calicostrado enlucido con cal, junto con verdugadas y alero superior de ladrillo. La cubierta fue acoplada mediante tableros, pares y tirantes de maderas, con cañizo y argamasa sobre los mismos y cierre final con tejas curvas de barro cocido. 
Figura 6: Alzados edificio principal Venta de Borondo.

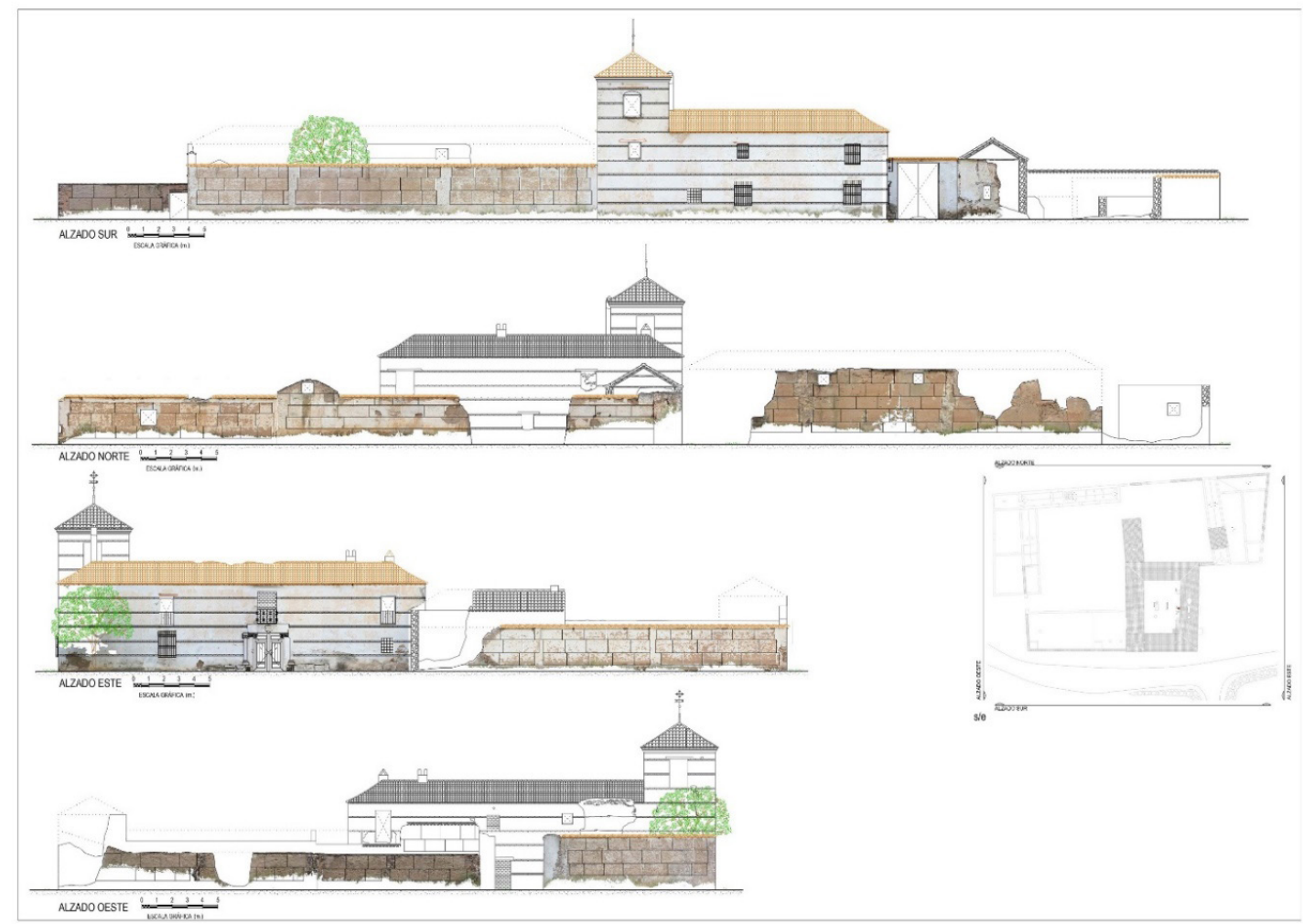

Fuente: David Cejudo.

Anexas a la edificación principal, hacia el norte y oeste, fueron erigidas una serie de instalaciones con una clara vinculación agropecuaria. Estuvieron formadas por cuadras, corrales y almacenes, así como por aposentos de las personas vinculadas con estas faenas. Fueron dispuestas con paredes de zócalo de mampostería de piedra y alzados de tapial, con una cubrición con techumbres de estructura de madera y cerramiento de teja curva a dos aguas. Quedaron distribuidas a partir de dos patios de dimensiones considerables con accesos a través de grandes puertas de madera, una sobre la nave oriental y otra sobre la occidental. En el patio situado más al este destaca la presencia de restos de un empedrado antiguo, compuesto por materiales calizos de mediano-pequeño tamaño trabados con tierra apisonada, similar a los otros apreciados en el inmueble.

Al noreste, aunque exento al recinto, se documenta un palomar de construcción reciente en el tiempo y de características similares al definido en la última fase de la torre. De igual manera, relacionado con esta casa, a unos $25 \mathrm{~m}$ hacia el norte se encuentra un pozo con noria y alberca, al estilo tradicional de los utilizados en toda la comarca, que permitió el abastecimiento de agua.

Por último, es mencionable un puente situado unos $100 \mathrm{~m}$ hacia el sur. Esta edificación está levantada sobre un arroyo que ha perdido su curso, pero que en épocas de gran pluviosidad ha llegado a recuperar su cauce hídrico, como ocurrió en el año 2013. Está formada por dos arcos 
de medio punto ejecutados con mampostería, al igual que los estribos, mientras que las bóvedas fueron levantadas mediante ladrillos. Todavía conserva, aunque no en muy buenas condiciones, la capa de rodadura, comprendida por piedras calizas trabadas con tierra apisonada. En líneas generales, su ergología constructiva es similar a la venta, aunque en este caso no se puede documentar la existencia de importantes transformaciones en el tiempo. El funcionamiento de esta infraestructura pudo estar relacionada con los caminos habilitados en esta zona y su comunicación con la Cañada Real Soriana Oriental, así como también para la explotación de los cultivos en sus inmediaciones, entre los que destacan olivares de cronología centenaria.

\section{Estado de conservación de la Venta Borondo}

A pesar de la representatividad y singularidad de este recurso, incluso su catalogación como BIC, el sitio no había sido objeto de ningún proyecto arqueológico o de rehabilitación hasta el año 2017. Hasta esa fecha únicamente son mencionables las tareas de mantenimiento realizadas por los propietarios, aunque desde hacía dos décadas no tenían continuidad. Por tanto, las condiciones en las que se encontraba el inmueble eran más que deficientes desde el punto de vista patrimonial.

Esta precaria situación era evidente en buena parte de su arquitectura, con lesiones especialmente notorias en determinadas partes como la torre central, la nave oeste y las cubiertas. Además, el desprendimiento progresivo de materiales de los paramentos estaba generando una pérdida de volúmenes en los mismos. Esta circunstancia implicaba un riesgo potencial para toda la composición, pudiendo llegar a significar un derrumbe definitivo. Asimismo, la abertura de vanos había generado filtraciones de agua pluvial, que a su vez generaba un mayor peso sobre los muros de carga.

De manera preliminar y pese a la ausencia de diagnósticos más exhaustivos, se percibían lesiones con un riesgo potencial para la integridad física y formal de la edificación, por lo que resultaba necesaria la intervención de manera urgente. Estas patologías eran más significativas en la torre central. En el tramo derecho de su fachada exterior oeste se observaba una pérdida de material de la sección del muro de tapial, llegando incluso a provocar que quedaran visibles capas internas, como puede advertirse en la figura 7.

La afección comprendía desde la parte más alta situada en el dintel del ventanal superior cegado hasta la planta baja. Esta pérdida suponía un riesgo manifiesto para la estabilidad de la torre, al afectar a los forjados y estructuras interiores. Además, se documentaba la caída de parte del alero y tejas de la cubierta. 
Como se ha comentado, había notables desprendimientos en la fachada exterior de la nave oeste. A grandes rasgos, se trataba de una lesión muy similar al caso anterior, con una importante pérdida de sección del tapial calicostrado desde el alero hasta la primera planta, llegando a distinguir los niveles interiores sin su capa de protección. Incluso, este impacto había dejado al descubierto la cara posterior de los arcaduces del palomar. De manera análoga, esta merma transmitía presiones sobre la viga-cargadero de la torre, así como se atestiguaba el desgaste y caída de aleros, caballetes y materiales de las cubiertas, especialmente en las naves oriental y occidental. Estos perjuicios favorecieron la desaparición de tramos del cerramiento, dejando a la vista el cañizo y la argamasa empleados en el cubrimiento y facilitando la apertura de vanos por los que entraba el agua pluvial. Igualmente, este problema estaba generando una sobrecarga en los forjados y la pudrición de las maderas.

Figura 7: Detalle de torre y exterior nave oeste antes de la intervención.

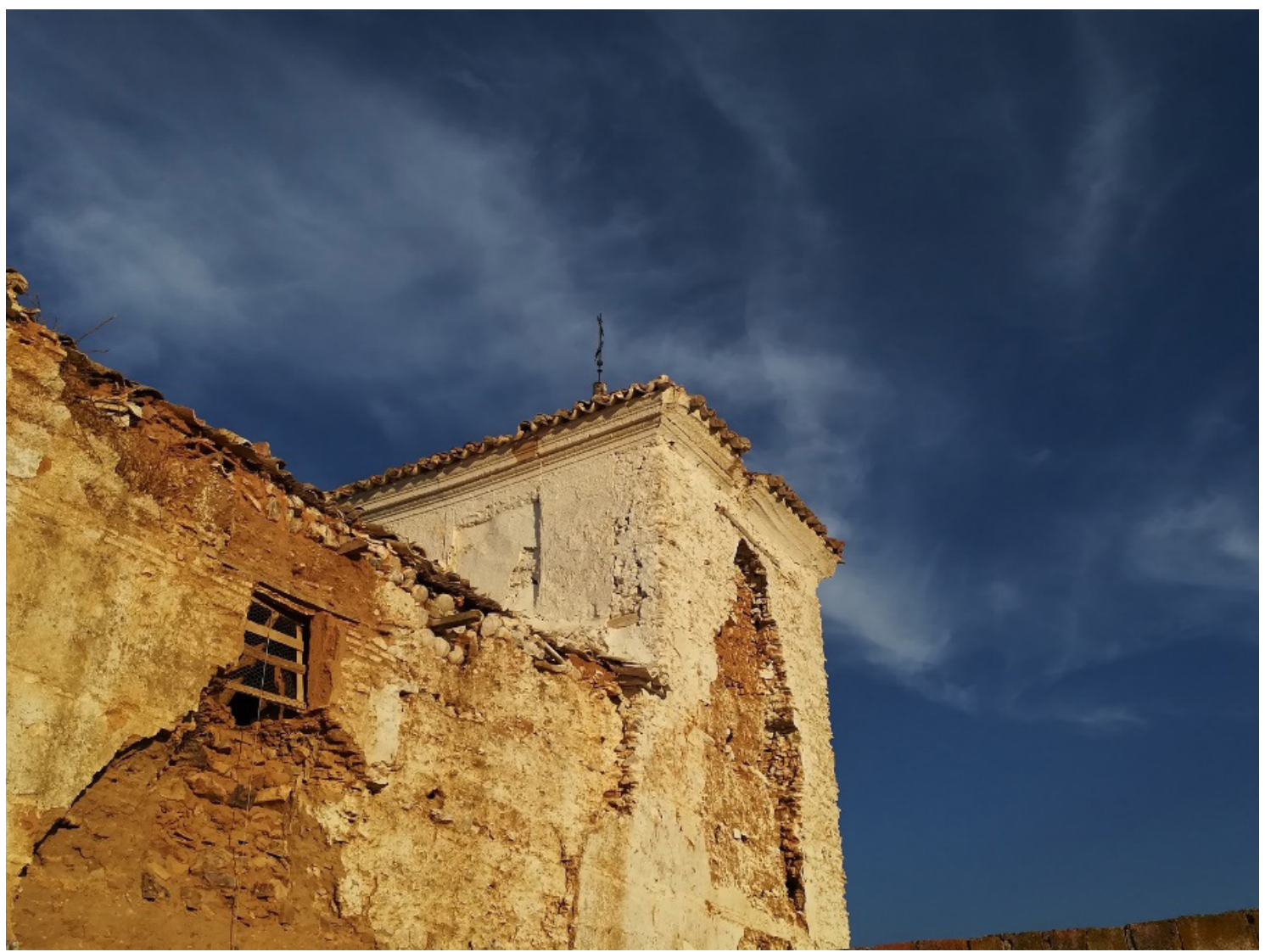

Fuente: Autores.

También era significativo el precario estado de las dos escaleras que permiten la subida desde el patio central al primer piso. La exterior, situada en el sector sureste, había perdido progresivamente buena parte de su cubierta de teja curva, por lo que se encuentra prácticamente 
abierta a la intemperie. Mientras, la emplazada al noreste, presenta un colapso casi completo de todos sus componentes, manteniéndose únicamente en pie algún peldaño de madera.

Ante esta realidad, resultaba necesario acometer una serie de labores que evitaran su ruina efectiva, participando de un programa amplio de actuaciones que facilitaran su conservación preventiva y revalorización. Por esta razón, desde el año 2017 se han emprendido diversas acciones relativas al estudio, preservación e interpretación de este bien tan excepcional.

\section{Actuaciones en la Venta de Borondo}

\subsection{Los primeros trabajos}

La degradación de todo el conjunto debido a la ausencia de labores mínimas de mantenimiento, había provocado la proliferación de elementos vegetales en prácticamente todo su perímetro. Ante esta perspectiva, los primeros trabajos fueron enfocados a una limpieza integral y a un desbrozado exhaustivo de toda la superficie. Se trató de una tarea preliminar, llevada a cabo durante el año 2017, que facilitó la visualización del recurso, a la vez que permitió aplicar medidas preventivas más efectivas y elaborar un diagnóstico más preciso sobre su estado.

Una vez retirada la vegetación existente fue instalada en determinados puntos una valla metálica a modo de cerramiento. Su objetivo fue el de evitar la entrada desde el exterior a zonas con problemas de desprendimiento de materiales o incluso con riesgo de desplome de paramentos. Se trataba de áreas que suponían un riesgo físico para la integridad de las personas, por lo que fue necesario habilitar un sistema disuasorio para impedir el acceso a sectores potencialmente peligrosos.

Concluida esta campaña se pudo evaluar la situación de la venta, comprobando de manera directa los daños y alteraciones que presentaban determinados tramos, al igual que permitió establecer las líneas prioritarias de actuación.

\subsection{Intervención de urgencia}

Acometidas estas primeras operaciones, limitadas desde el punto de vista de las necesidades del bien, se estimó la prioridad de ejecutar unas serie de tareas que permitieran detener la degradación de zonas con riesgo potencial de derrumbe y/o pérdida irreparable. 
En líneas generales, se pretendía potenciar una valorización efectiva de todo el monumento. Analizadas y definidas las actuaciones más urgentes, se decidió enfocar los esfuerzos hacia la torre y a la fachada exterior de la nave occidental ${ }^{31}$.

Con respecto a la actuación, de manera previa se efectuó una documentación exhaustiva de los sectores a intervenir, incluyendo una lectura de paramentos de los tramos abordados. Igualmente, fue realizado un análisis sobre las características funcionales, constructivas y formales del inmueble, o de los diferentes procesos históricos edilicios, incluyendo la identificación de aquellos materiales tradicionales empleados, con el objetivo de poder respetar sus características y componentes en la nueva intervención. En todo momento, se ha tratado de salvaguardar la configuración original de la venta, respetando aquellos parámetros que han permitido reconocer un legado tan singular para el patrimonio cultural castellano-manchego. Asimismo, el proyecto se ha adaptado a las peculiaridades del edifico, consolidando aquellas alteraciones manifestadas sin modificar o alterar su fisonomía.

El proyecto ha seguido aquellos criterios definidos como imprescindibles para trabajos de restauración y rehabilitación ${ }^{32}$, como el principio de mínima intervención, actuando solo en aquellas zonas previstas y respetando en todo momento los materiales y técnicas que configuran el monumento; reversibilidad de los tratamientos, con la utilización de productos y métodos que no han alterado las propiedades físico-químicas de los materiales constructivos; discernibilidad de los trabajos, a través de la instalación de un "estrato o línea de intervención" de malla de fibra de vidrio, entre los paramentos originales y las zonas rehabilitadas o en aquellos puntos donde ha sido necesaria la aplicación de un "estrato de sacrificio". En la actuación se ha tratado de preservar los rasgos distintivos de la estructura original, conservando aquellos componentes posibles o empleando materiales que fueran lo más afines a la composición histórica del inmueble. Igualmente, se prescindió del uso de morteros con cementos, utilizando mezclas con cal, que cuenta con propiedades más precisas para estas labores y representa una sustancia más respetuosa con la arquitectura existente.

Con respecto a las operaciones acometidas durante esta campaña, destacaron las acciones para la reposición de los paramentos de tapial y mampostería perdidos en la fachada exterior de la torre y la nave oeste. La caída de materiales y volúmenes había originado grandes oquedades en estas paredes, llegando incluso a dejar al descubierto niveles interiores del tapial. Stricto sensu, esta circunstancia suponía un riesgo importante de colapso de estos sectores. En virtud de estas debilidades, fue oportuno aplicar de manera inicial una capa ligera de mortero de cal sobre la zona a intervenir, con el fin de fijar todo el ámbito para poder trabajar con las mejores garantías de seguridad, así como para lograr una transpiración más efectiva de los materiales.

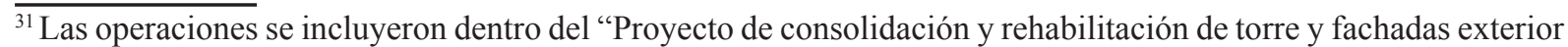
oeste y cubiertas en Venta de Borondo", que contó con la aprobación de la Viceconsejería de Cultura de la Junta de Comunidades de Castilla-La Mancha.

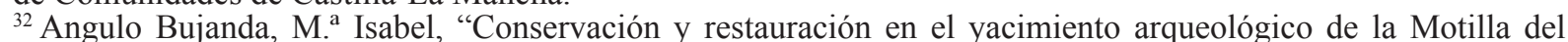
Azuer, campañas 2015 y 2016”, en IV Jornadas de Historia de Daimiel, Ayuntamiento de Daimiel, 2018, p. 33.
} 
Una vez estabilizado el lienzo, y colocado el estrato de intervención, se fue recomponiendo la pared de mampostería y tapial, siguiendo los mismos parámetros de la tipología presente en el resto de la fachada. La solución propuesta fue una argamasa con una fórmula compuesta por tierra del entorno, arena, grava y cal, en diversas proporciones en función del espesor y volumen a reintegrar, que lograba mantener una textura y tonalidad similar a la tradicional. La disposición del relleno ha sido variable en función de la realidad existente en la composición, incorporando incluso estacas de madera hidrófugas, a modo de cosido, como refuerzos en las zonas de mayor pérdida de volumen. Esta solución ha logrado reforzar esta área, sin que ello constituyera un mayor peso para su estabilidad.

Figura 8: Imagen durante el desarrollo de los trabajos.

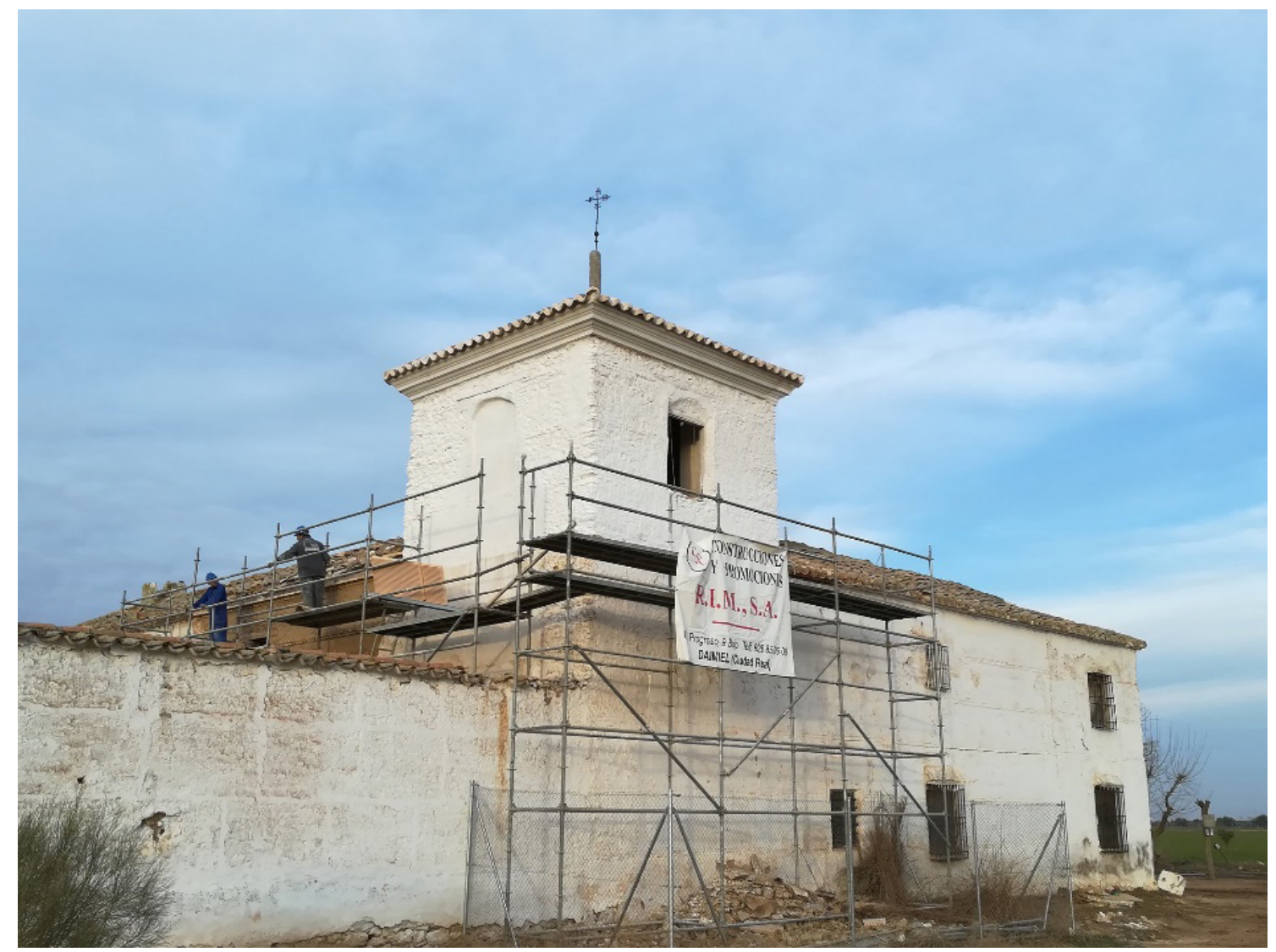

Fuente: Autores.

El proceso de restitución se ha efectuado de abajo hacia arriba, sin necesidad de introducir ningún tipo de encofrado. En la mampostería se han empleado las propias piedras caídas. Por su parte, en los tramos de verdugadas de ladrillos se han recuperado aquellas piezas válidas o se han incorporado nuevas bajo las mismas características, prolongando el mismo patrón compositivo. La reposición ha tratado de igualar la sección de muralla con respecto a la superficie presente. El revoco final del muro se ha realizado con un preparado de cal hidráulica, continuando con 
la misma técnica de las unidades preexistentes, con la ligera variación de dejarlo levemente rehundido, apenas unos milímetros, con el objetivo de poder distinguir de manera precisa el ámbito restaurado del no intervenido. También se estimó en la aplicación del mortero respetar un tiempo prudencial para el secado de la cal, favoreciendo la adecuada carbonatación de este material.

Figura 9: Fachada nave oeste tras la intervención.

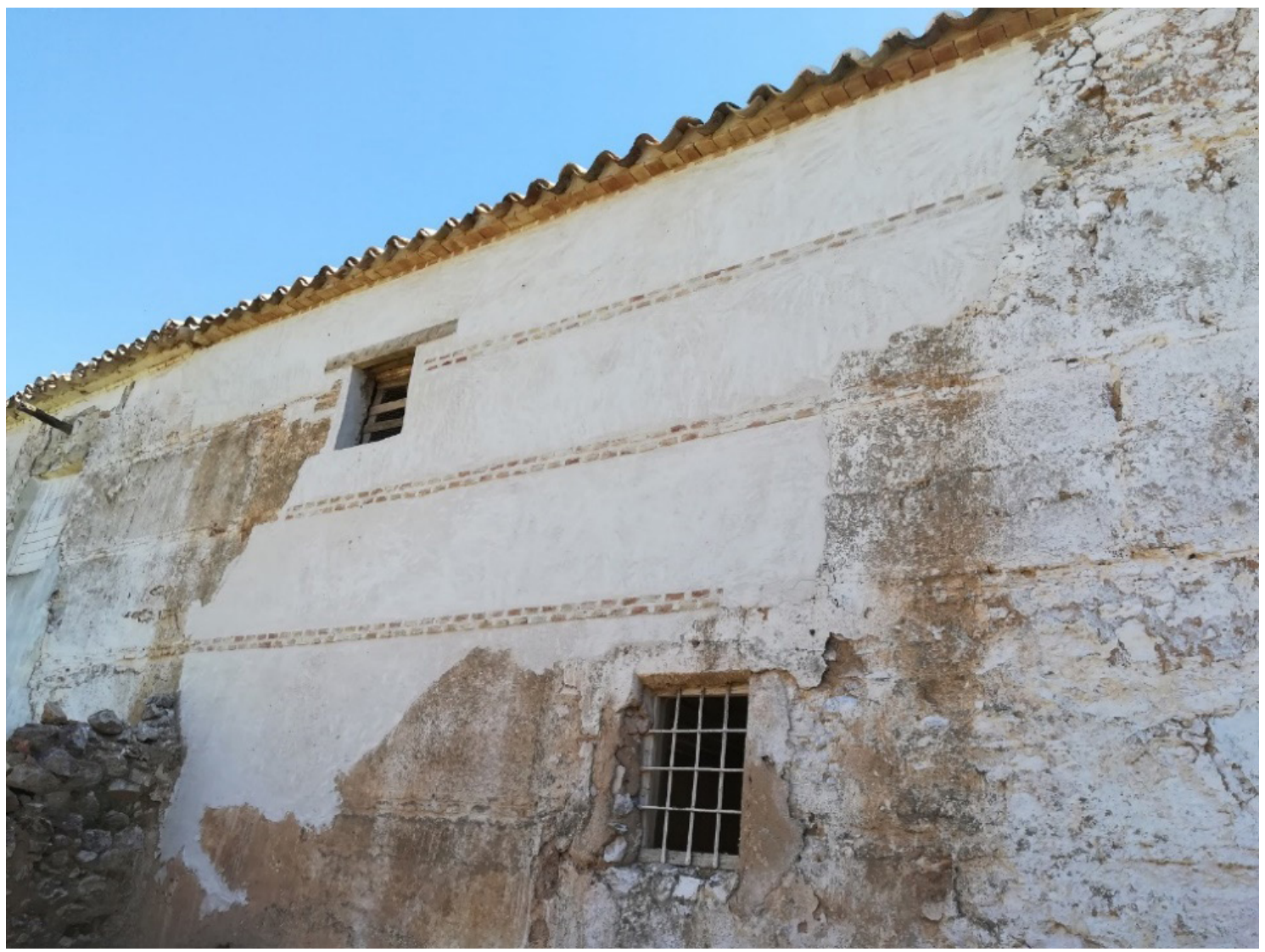

Fuente: Autores

Otra de las grandes actividades proyectadas fue la intervención en las cubiertas, concretamente las pertenecientes a la torre y las naves adyacentes. En este sentido, se estimó prioritario proceder a renovar aquellos componentes de madera que se pudieran encontrar dañados. La retirada de tejas permitió evaluar la situación real del interior de la cubrición, incluyendo toda la estructura de madera que soporta la misma. Una grata noticia fue advertir que casi la totalidad de las maderas se encontraban en buenas condiciones, por lo que sólo fue preciso retirar y sustituir uno de los pares, el situado más al sur. Posteriormente, fue instalado un tablero de ripia de pino gallego, con aislante tipo poliestireno extruido adherido mediante banda. Por encima fue aplicado un mortero de cal y arena, sobre el cual se han ido colocando progresivamente las tejas, recuperando aquellas unidades originales en los costados de las 
hiladas de tejas soleras, así como relleno bajo la cobija. Concluidos estos procesos, se efectuó el emboquillado de las situadas en el alero. Asimismo, la moldura del alero de la torre ha sido reparada y repuesta en aquellos puntos en los que había desaparecido o en los que se había detectado la presencia de grietas que suponían un riesgo para su morfología. En los fragmentos cuarteados se ha procedido a reintegrar la escayola, mientras que en las partes perdidas se ha reproducido en el mismo material una moldura ex novo, obteniendo los volúmenes y dimensiones de aquellas piezas que se encontraban saneadas. Las secciones añadidas han sido sujetadas con esparto, respetando la técnica original a través de cuerdas trenzadas que cumplían esta función.

Figura 10. Vista de la Venta después del proyecto de actuación.

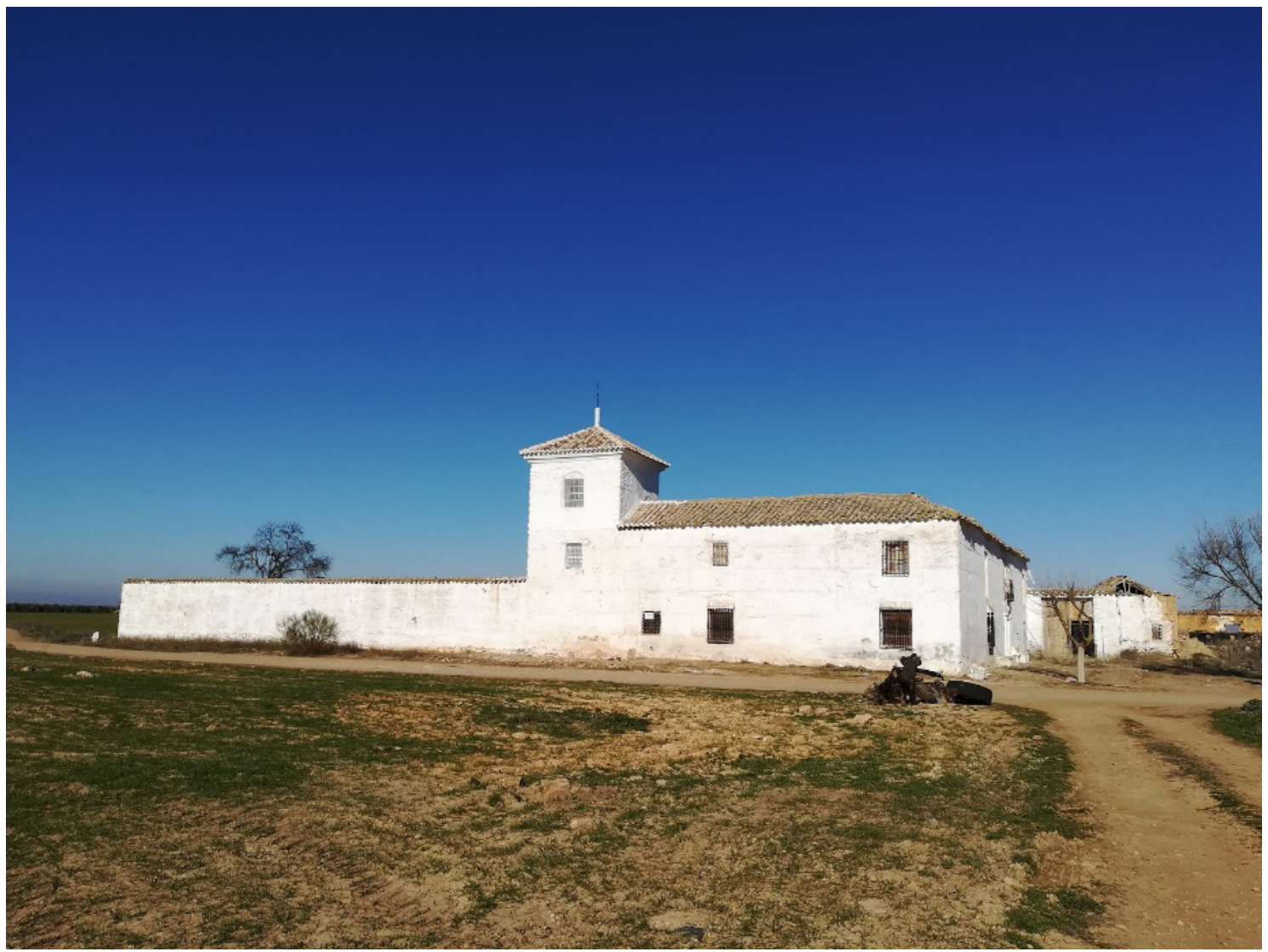

Fuente: Autores.

Igualmente, se ha procedido a la restitución de dos cubiertas correspondientes a la nave meridional y occidental, concretamente en los puntos de contacto con la torre. La degradación de estos espacios estaba provocando el traslado de presiones sobre la estructura de la madera y la entrada de agua a los muros laterales. Debido a esta realidad se apreció conveniente la reparación integral de estos sectores, siguiendo las mismas directrices que las planteadas en la torre. Así, fue retirada la teja existente para establecer un diagnóstico preciso del interior. Se constató las buenas condiciones que presentaban la mayoría de estructuras de madera, aunque sí 
fue oportuno retirar la ripia de madera, el yeso y el cañizo. También fue acomodado un tablero de similares características al de la torre. Sobre estos elementos ha sido aplicado un mortero de cal y arena sobre el que se han ido reponiendo las tejas, siendo posible aprovechar buena parte de las originales, ya que se encontraban en buen estado de conservación.

Además, la presencia del andamiaje de seguridad facilitó llevar a cabo una serie de reparaciones de carácter menor. Se trataba de componentes que se estaban viendo afectados por la acción de agentes erosivos y que debido a la ausencia de labores de mantenimiento o reparación, en parte por la dificultad de acometer esos trabajos, se consideró oportuno proceder a su renovación. Por ejemplo, se emprendió la reparación de la veleta, emblema de este sitio histórico, que fue limpiada y pintada con pintura negra de forja. El propio mástil de madera que sostiene la veleta fue tratado con una resina específica y recubierto con pintura especial para resina. Asimismo, fue rehabilitada la reja de la ventana del segundo cuerpo de la fachada meridional.

\section{Conclusiones. Las posibilidades patrimoniales de la Venta de Borondo en la actualidad}

La Venta de Borondo por su arquitectura, significado histórico y representatividad supone un bien excepcional para Daimiel y la provincia de Ciudad Real. Constituye uno de los últimos exponentes de unas expresiones particulares y notorias como fueron las ventas de llanura, testimonios materiales del pasado de esta región durante varios siglos.

Una posición privilegiada en virtud de los paradigmas de cada época, junto con la presencia de superficies aptas para su explotación agropecuaria, favorecieron el establecimiento humano desde tiempos pretéritos. Se han evidenciado vestigios de la ocupación de este paraje desde la Edad del Hierro, que nos pueden inferir en el desarrollo de un asentamiento desde el mundo íbero-oretano con continuidad en el horizonte romano, aunque la falta de investigaciones específicas supone una limitación para su definición completa. Este establecimiento pudo articularse en relación con diferentes arterias de comunicación que transitaban en este territorio y posiblemente vinculado con uno de los grandes oppida de esta comarca como Cerro de Las Cabezas (Valdepeñas), Oreto (Granátula de Calatrava), Alarcos (Ciudad Real) o Los TorilesCasas Altas (Villarrubia de los Ojos/Daimiel).

Sobre esta ocupación, aunque sin identificar una secuencia de continuidad en el tiempo, a partir del período bajomedieval-moderno fue habilitada una hospedería para el descanso y reposo de los viajeros, participando de las diversas rutas que vertebraban la península desde la Meseta 
Norte a Andalucía. También tuvo cierto vínculo con los movimientos de ganados trashumantes, de importante trascendencia económica y social para ciertos territorios. Esta orientación, unida al referente visual que simbolizaba dentro del paisaje, facilitó su reconocimiento por los habitantes de la zona, así como por las personas que recorrían este ámbito. Uno de ellos pudo ser Miguel de Cervantes, que quizás se inspiró en su imagen a la hora de representar estas construcciones en su obra. Indudablemente, no afirmamos que se trate exactamente del lugar en el que este escritor situó varios pasajes literarios de Don. Quijote de La Mancha, ni es el motivo de este trabajo, pero la Venta de Borondo representa un inmueble de la tipología recogida en esa novela, cuyas características todavía son apreciables en este caso.

En definitiva, la gran representatividad de este monumento es que ha logrado conservar buena parte de su arquitectura histórica, en la que se distinguen las particularidades de las construcciones vernáculas de la región. Las técnicas y materiales constructivos, la distribución de espacios, el aprovechamiento de recursos naturales o su adaptación al entorno geográfico, visibles todos ellos en la venta, también reflejan las pautas de estas expresiones.

No obstante, a pesar de la singularidad que atesora y de su clasificación como BIC en el año 2007, en las últimas décadas no se habían realizado tareas de mantenimiento y conservación en su interior. Por esta razón, en el año 2016 se encontraba en peligro de ruina inminente. Esta situación provocó la movilización de un colectivo ciudadano para la defensa de este recurso, razón por la cual se constituyó la Asociación Cultural Venta de Borondo y Patrimonio Manchego, con la misión fundamental de luchar por el estudio, preservación y difusión de un activo patrimonial tan importante. Esta agrupación, a pesar de sus escasos medios económicos y humanos, está consiguiendo detener el deterioro progresivo y facilitar su comprensión, aunque todavía queda un largo recorrido en su protección e interpretación.

Los trabajos emprendidos en las campañas de 2017 y 2018 ha resultado un éxito desde el punto de vista de la valorización de este monumento. En este sentido, han permitido desarrollar una documentación exhaustiva de todo su conjunto, estableciendo un diagnóstico certero de patologías y afecciones existentes. En los mismos términos, se ha acometido un análisis sobre los rasgos constructivos, funcionales y formales del inmueble, favoreciendo determinar los diferentes procesos históricos documentados. En todo momento, se ha tratado de salvaguardar la configuración original, respetando los rasgos que han permitido reconocer un legado excepcional del patrimonio cultural de Castilla-La Mancha. Por esta razón, en la intervención se han respetado los materiales tradicionales, con el objetivo de mantener sus propiedades y componentes. Igualmente, en los últimos meses se están efectuando estudios que permitan avanzar en la compresión y preservación de la Venta de Borondo, entre los que destaca la digitalización integral de sus espacios o la aplicación de un encalado todos los años.

En líneas generales, corresponde con actuaciones muy positivas para el conocimiento, conservación y divulgación de este recurso, dentro de una concepción rigurosa, activa y amplia 
73 Miguel Torres, David Cejudo, M. ${ }^{a}$ Isabel Angulo, Honorio Álvarez, "Venta de Borondo..." de las operaciones emprendidas. Estas tareas participan de una estrategia integral, que fomente una gestión adecuada y eficaz de un bien extraordinario como el mostrado en estas páginas. 